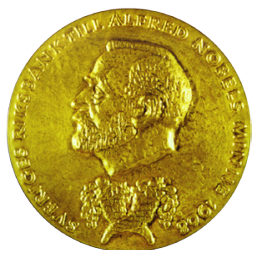

Scientific Background on the Sveriges Riksbank Prize in Economic Sciences in Memory of Alfred Nobel 2011

\title{
EMPIRICAL MACROECONOMICS
}

compiled by the Economic Sciences Prize Committee of the Royal Swedish Academy of Sciences 



\section{Empirical Macroeconomics Thomas J. Sargent and Christopher A. Sims}

One of the main tasks for macroeconomists is to explain how macroeconomic aggregates - such as GDP, investment, unemployment, and inflation - behave over time. How are these variables affected by economic policy and by changes in the economic environment? A primary aspect in this analysis is the role of the central bank and its ability to influence the economy. How effective can monetary policy be in stabilizing unwanted fluctuations in macroeconomic aggregates? How effective has it been historically? Similar questions can be raised about fiscal policy. Thomas J. Sargent and Christopher A. Sims have developed empirical methods that can answer these kinds of questions. This year's prize recognizes these methods and their successful application to the interplay between monetary and fiscal policy and economic activity.

In any empirical economic analysis based on observational data, it is difficult to disentangle cause and effect. This becomes especially cumbersome in macroeconomic policy analysis due to an important stumbling block: the key role of expectations. Economic decision-makers form expectations about policy, thereby linking economic activity to future policy. Was an observed change in policy an independent event? Were the subsequent changes in economic activity a causal reaction to this policy change? Or did causality run in the opposite direction, such that expectations of changes in economic activity triggered the observed change in policy? Alternative interpretations of the interplay between expectations and economic activity might lead to very different policy conclusions. The methods developed by Sargent and Sims tackle these difficulties in different, and complementary, ways. They have become standard tools in the research community and are commonly used to inform policymaking.

Background Prior to the 1970s, expectations played, at best, a rudimentary role in the analysis of macroeconomic outcomes. Following the seminal work by Milton Friedman, Robert Lucas, Edmund Phelps, and others, it became necessary to systematically incorporate expectations not only into macroeconomic theory, but also - and more importantly - into its empirical implementation. This was a major obstacle, however. At the time, formal methods were simply not available to identify and analyze exogenous shocks, 
as a means of evaluating macroeconomic theories that feature "active" formation of expectations.

Sargent and Sims have both made seminal contributions that allow researchers to specify, empirically implement, and evaluate dynamic models of the macroeconomy with a central role for expectations. Their subsequent work, from the initial papers until today, has delivered many extensions, refinements, and powerful applications. The contributions by Sargent and Sims have generated literatures of methodological research and applied studies within the research community as well as the policymaking community.

Prior to the formative research by Sargent and Sims, the predominant empirical method in macroeconomics was to statistically estimate a large linear system, typically built around the Keynesian macroeconomic model. This estimated system was then used to interpret macroeconomic time series, to forecast the economy, and to conduct policy experiments. Such large models were seemingly successful in accounting for historical data. However, during the 1970s most western countries experienced high rates of inflation combined with slow output growth and high unemployment. In this era of "stagflation", instabilities appeared in the large models, which were increasingly called into question.

Sargent - structural econometrics Sargent began his research around this time, during the period when an alternative theoretical macroeconomic framework was proposed. It emphasized rational expectations, the notion that economic decisionmakers like households and firms do not make systematic mistakes in forecasting. This framework turned out to be essential in interpreting the inflation-unemployment experiences of the 1970s and 1980s. It also formed a core of newly emerging macroeconomic theories.

Sargent played a pivotal role in these developments. He explored the implications of rational expectations in empirical studies, by showing how rational expectations could be implemented in empirical analyses of macroeconomic events - so that researchers could specify and test theories using formal statistical methods - and by deriving implications for policymaking. He also advanced and applied broader views on expectations formation, such as gradual learning. Sargent's contributions to rational-expectations econometrics were purely methodological. Specifically, his methods for characterizing and structurally estimating macroeconomic models with microeconomic foundations broke new ground in allowing researchers to uncover the "deep" 
underlying model parameters and perform hypothesis testing. In a broader perspective, Sargent also raised important points of immediate policy relevance. For example, his early studies of linkages between fiscal and monetary policy still guides policymakers still today.

Sims - VARs Sims launched what was perhaps the most forceful critique of the predominant macroeconometric paradigm of the early 1970 s by focusing on identification, a central element in making causal inferences from observed data. Sims argued that existing methods relied on "incredible" identification assumptions, whereby interpretations of "what causes what" in macroeconomic time series were almost necessarily flawed. Misestimated models could not serve as useful tools for monetary policy analysis and, often, not even for forecasting.

As an alternative, Sims proposed that the empirical study of macroeconomic variables could be built around a statistical tool, the vector autoregression (VAR). Technically, a VAR is a straightforward $N$-equation, $N$-variable (typically linear) system that describes how each variable in a set of macroeconomic variables depends on its own past values, the past values of the remaining $N-1$ variables, and on some exogenous "shocks". Sims's insight was that properly structured and interpreted VARs might overcome many identification problems and thus were of great potential value not only for forecasting, but also for interpreting macroeconomic time series and conducting monetary policy experiments.

Over the last past three decades, the VAR methodology has been developed significantly in various directions, and Sims himself remained at the forefront. As a result, VARs are now in ubiquitous use, among empirical academic researchers and policymaking economists alike. By now, VARs also constitute a major research tool in many areas outside of monetary economics.

Applications Both Sargent and Sims have used their own methods in influential applications concerning the determinants and effects of monetary policy. In a series of contributions, Sargent has analyzed episodes of very high inflation, or hyperinflation. He explored the high inflation in the U.S. during the 1970s and subsequent changes that brought about a rapid, and seemingly permanent, fall in inflation. In this analysis, Sargent found that learning a departure from fully rational expectations - is important in order to un- 
derstand how inflation came and went. In fact, the defining characteristic of Sargent's overall approach is not an insistence on rational expectations, but rather the essential idea that expectations are formed actively, under either full or bounded rationality. In this context, active means that expectations react to current events and incorporate an understanding of how these events affect the economy. This implies that any systematic change in policymaking will influence expectations, a crucial insight for policy analysis.

Sims has also carried out many applied studies, to some extent on the very same topics, i.e., the extent and implications of monetary policy shifts in the U.S. His main focus, however, has been on the identification of unexpected policy changes and their effects on economic activity. With regard to the crucial distinction between expected and unexpected, Sims's method offers a means of separating expected from unexpected policy changes as drivers of macroeconomic variables. His method has gained broad acceptance and has, for example, allowed us to establish how unexpected monetary policy changes lead to immediate effects on some macroeconomic variables but only slow, and hump-shaped, effects on others. Indeed, some of the most influential studies of this issue were undertaken by Sims himself.

Later work Sargent and Sims are actively pursuing new research aimed at further understanding expectations formation and its role in the economy. Sargent's focus here is on exploring a class of mechanisms for expectations formation based on robust control, which captures the idea that the decisionmaker has an imperfect understanding of how the economy works. Similarly, Sims's most recent work explores a parallel, new theory for expectations formation based on rational inattention, which captures agents' limited capacity to process information.

Relations between the two strands of work Although Sargent's and Sims's empirical methodologies certainly differ, they complement one another and are often used in conjunction. In fact, the dynamic behavior of a Sargent-style structural model with rational expectations can often be represented as a Sims-style VAR. Identification of such a VAR would then directly correspond to identification of the structural parameters estimated along the lines of rational-expectations econometrics. A key aspect of VAR methodology, so-called impulse-response analysis, describes how fundamental shocks propagate through the macroeconomy. It has become a leading 
method for describing and analyzing structural macroeconomic models. Conversely, VAR identification is often made with specific reference to structural models, although such "structural" VAR identification typically refers to classes of models rather than a specific model. Which of these approaches is followed in a specific application depends on the purpose. Structural estimation is straightforwardly implemented with modern computers and is particularly useful for analyzing policy regimes. VAR analysis, which relies on fewer and less specific theoretical assumptions, is mainly used for identifying what policy shocks have occurred and their likely effects, absent a change in policy regime. The methods developed by Sargent and Sims thus comprise a methodological core in modern empirical analyses of macroeconomic policy and economic activity.

Outline of this survey In what follows, Sargent's and Sims's key contributions are described separately in Sections 1 and 2. Section 3 provides an elaborate example of how the methods are interrelated, while also allowing for a more precise description of Sargent's methodology. Section 4 offers a brief account of the aforementioned work on robust control and rational inattention. Section 5 concludes.

\section{Structural Estimation and Active Expecta- tions: Contributions of Thomas J. Sargent}

\subsection{Historical context and impact on current work}

Sargent's research began at a time when a group of economists - among them the previous laureates Lucas, Phelps, and Prescott - had upset the prevailing macroeconomic paradigm based on reduced-form models. They proposed a new macroeconomics where expectations would play a pivotal role. More generally, they insisted on the need to rebuild macroeconomic theory and empirical methodology. The new theory would be based on models with "microeconomic foundations", i.e., a theory of key economic decisions that would be invariant to changes in policy. The new empirical methodology would be based on estimation of the structural parameters in these models, for example parameters describing individual preferences and production functions. Sargent was a highly influential and distinguished member of this "rational-expectations group". 
As a result of this new research program, macroeconomics changed course rather drastically. Views on policy were transformed, and the awards to Lucas and Phelps were largely motivated by the policy implications of their work. Views on business cycles also changed, due to the contributions of Lucas and Sargent as well as later work by Kydland and Prescott. More recently, Keynesian ideas Keynesian ideas have been revived in a "New Keynesian Macroeconomics", which builds directly on Kydland and Prescott, with the addition of various frictions such as sticky prices and wages. Modern empirical macroeconomic research relies heavily on structural-estimation methods, of which Sargent is the main architect.

\subsection{Empirical methods and early applications}

In the early to mid- 1970s, Sargent wrote a number of highly influential papers, where he showed how rational expectations implied a radical reinterpretation of empirical macroeconomic phenomena and rendered invalid conventional statistical tests of macroeconomic relations, such as the FriedmanPhelps hypothesis on the Phillips curve. Taken together, these papers had a profound impact on central hypotheses about the role of monetary policy and the Phillips-curve tradeoff.

Compared to other researchers at the time, Sargent focused more on actual data and on ways to evaluate theory by taking active expectations formation into account. He was thus able to show why earlier tests had gone wrong and how new, more accurate, tests could be constructed.

Sargent's general approach was to formulate, solve, and estimate a structural macroeconomic model with microeconomic foundations, i.e., a system where all parameters, except those describing policy, are invariant to policy interventions. Once its parameters are estimated, the model can be used as a "laboratory" for analyzing policy experiments. (See Section 3 for a detailed description of how this is carried out in the context of a specific example.)

Empirical applications Sargent combined the development of general methods with concrete empirical applications. In a series of papers, he helped to construct what later became an indispensable empirical method in modern macroeconomics.

In a very early contribution - which predated Lucas's work on the same topic - Sargent (1971) demonstrated the crucial role of expectations in econometric studies of the Phillips curve. A vital question in such studies had been 
whether the long-run Phillips curve is vertical or has some (negative) slope, as does the short-run curve. Sargent demonstrated that the usual econometric tests relied critically on regarding expectations as passive, and that the forward-looking nature of rational expectations implied that expectations themselves depend on the slope of the long-run Phillips curve. This made earlier rejections of a vertical Phillips curve invalid and indicated that the curve could well be vertical. Since Sargent's article, other efforts have been made to pin down the slope of the long-run Phillips curve; see, e.g., Galí and Gertler (1999) for a discussion.

Sargent (1973) carried out the first successful econometric estimation under rational expectations. It was based on a simple but complete model of the U.S. economy, which embedded Irving Fisher's theory that nominal interest rates should increase one for one with expected inflation. Sargent showed that a test of Fisher's theory also amounted to a test of the natural-rate hypothesis. His econometric evidence implied rejection of the theory (although with rather low statistical significance). This paper served as a model for all empirical applications to follow.

Sargent (1976) constructed and estimated an econometric model of the U.S. economy subject to both real and nominal shocks. The estimation results in this study gave the first indications that models with real shocks, to be studied later by Kydland and Prescott, might be empirically successful.

Further important contributions by Sargent in the area of macroeconomics include Sargent (1978a) and the joint paper with Hansen and Sargent (1980). In the area of forecasting, Sargent and Sims (1977) developed "index modeling", later extended by Quah and Sargent (1993). Sargent (1989) showed how filtering methods could be used to estimate linear rationalexpectations models in the presence of error-ridden data.

Among Sargent's most recent applied contributions, Sargent and Surico (2011) is noteworthy in showing how standard tests of the quantity theory of money - a pillar of the monetarist view - are sensitive to the past monetary policy regime. Using structural estimation as well as VARs, the authors argue that apparent breakdowns of the quantity theory can instead be explained by changes in the policy regime.

Many of the principal methods are collected in Sargent's two monographs Macroeconomic Theory (1979) and Dynamic Macroeconomic Theory (1987), and in Rational Expectations and Econometric Practice (1981), a volume coedited by Lucas and Sargent. These publications have constituted required reading for generations of macroeconomic researchers. 


\subsection{Policy implications}

From the perspective of macroeconomic theory, the nature of expectations is crucial for the effectiveness of various forms of economic policy. An important part of Sargent's work explores the restrictions rational expectations place on policymakers. Sargent and Wallace (1976) and a series of papers that followed, showed how merely replacing adaptive expectations with rational expectations dramatically altered the policy implications of then-standard macroeconomic models. Other work in this series include Sargent and Wallace $(1973,1975)$. As these papers were cast in traditional macroeconomic models, they added significantly to Lucas's $(1972,1973)$ seminal work on expectations and monetary policy, which had departed from traditional macroeconomics in its aim to develop a new theory of inflation-output correlations.

Sargent and Wallace (1981) explored the connections between fiscal policy and monetary policy. They argued that monetary and fiscal policy were inexorably linked, thereby demonstrating how Friedman's assertion that "inflation is always and everywhere a monetary phenomenon" can be quite misleading. As the paper shows, fiscal policy may force monetary policy to become highly inflationary. The basic argument is that monetary policy generates seigniorage, i.e., real revenue that contributes to government financing, and that this seigniorage may become necessary in the wake of large budget deficits. Thus, current fiscal deficits may require higher future inflation in order for the intertemporal budget to balance. ${ }^{1}$

Sargent's analysis of how monetary and fiscal policy influences real activity has also guided empirical work, where researchers have had to deal with the Lucas critique, i.e., how the effects of policy change can be studied using historical data. Lucas argued that this would require identifying deep structural parameters, which traditional macroeconometric techniques did not allow for. In response to this argument, Sargent and Sims have pursued different, but complementary paths. Sargent has focused precisely on identifying structural parameters, while Sims has focused on ways of isolating the effects of policy shocks without estimating deep structural parameters.

\footnotetext{
${ }^{1}$ The argument is closely related to recent suggestions, by e.g., Woodford (1994) and Sims (1994), that fiscal policy can also be a determinant of the current level of prices, again through the government budget constraint. The "fiscal theory of the price level" argues that the nominal price level adjusts so that the real value of fiscal authorities' initial nominal debt clears the intertemporal government budget (without a need for inflation/seigniorage finance). While the unpleasant monetarist arithmetic is broadly accepted, the fiscal theory of the price level remains controversial.
} 
(These issues are further discussed in the context of the simple example in Section 3.)

\subsection{Episodes of high inflation}

Sargent has pursued important research on episodes with high inflation, especially hyperinflation. This work includes an early paper "The Ends of Four Big Inflations" (1983), which analyzes historical hyperinflations in Europe. It may also be found in his book, The Conquest of American Inflation (2001), which studies how inflation in the United States rose in the 1970s and then gradually fell, as illustrated in Figure 1. The book emphasizes learning and less than fully rational expectations (adaptive expectations are considered as well and turn out to be important). It builds on Sargent's earlier joint work with Albert Marcet, e.g., Marcet and Sargent (1989a,b). ${ }^{2}$

\footnotetext{
${ }^{2}$ In the 1980s, a series of papers by Sargent and Marcet, one of Sargent's students, explored learning in macroeconomic analyses. Learning embodies two elements: (i) agents' incomplete knowledge of some model parameters, and (ii) a specification of how agents learn about these parameters, based on observations of evolving time-series data. Marcet and Sargent made reference to a literature in economic theory on how economic agents learn under different circumstances.

Their contribution was to specify a plausible learning mechanism-typically "leastsquares learning", by running OLS regressions - and explore its implications. Learning can thus be viewed as a model of how expectations are formed. A central question becomes whether such endogenous formation of expectations naturally tends toward rationality, i.e., full knowledge of the model. A subsequent literature developed to explore this question in a variety of settings (see Evans and Honkapohja, 2001 for an overview). Learning has not yet become a standard part of modern macroeconomic models, but there is increasing recognition of its importance and the number of applications is growing.
} 


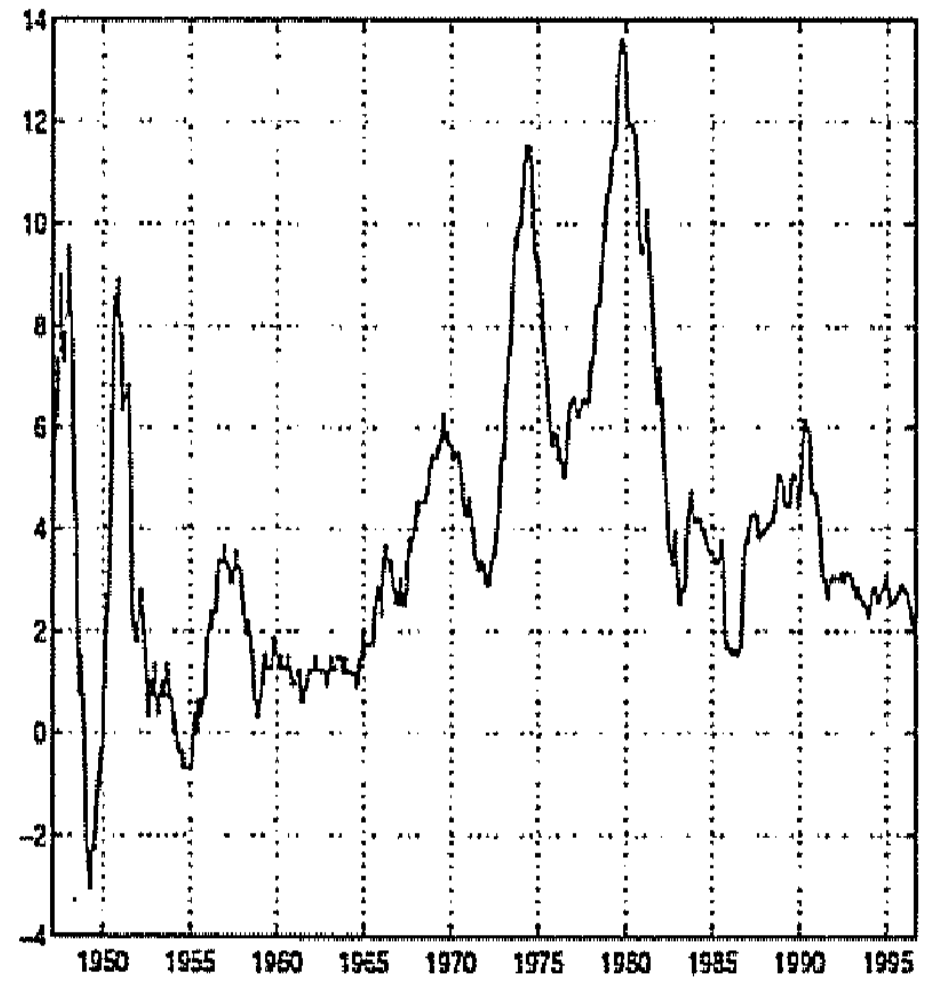

Figure 1. Inflation in the U.S., 1950-1995. The y axis displays inflation in percent and the $\mathrm{x}$ axis displays years.

A recent contribution by Sargent, Williams, and Zha (2006) is a good illustration of Sargent's views and methods for analyzing the dynamics of inflation. This paper considers a monetary authority that explicitly maximizes consumer welfare and has specific beliefs about the Phillips curve. In particular, the central bank does not believe in an "expectations-augmented" Phillips curve, but in a time-varying curve, while the private sector has rational expectations, so the "true" curve is indeed expectations-augmented. The authors estimate this model structurally using a Bayesian Markov chain Monte Carlo method and find that it fits the data quite well. Their estimates suggest that the central bank was initially "fooled" by an incorrect belief about the Phillips curve, which led to a gradual increase in the inflation rate. But the sequence of shocks in the 1970s, along with a revision of the central bank's beliefs, generated a subsequent fall in inflation. Quite 
surprisingly, the model's forecasting ability outperforms that of advanced atheoretical forecasting models (Bayesian VARs). What really occurred during the 1970s and how the lessons from these experiences can be exploited in modern policymaking remains a subject of considerable debate. Despite this, Sargent's historical interpretations are important benchmarks against which current research has to measure up.

\section{The Analysis of Macroeconomic Shocks: Contributions of Christopher A. Sims}

\subsection{Historical context and impact on current work}

At the time when Sims launched vector autoregression (VAR) methods, the predominant empirical approach in macroeconomics was to estimate a large system of equations built around a Keynesian macroeconomic model. Such estimated systems were used for interpreting the time series, forecasting, and conducting policy experiments. In a landmark contribution, Sims (1980) argued that the resulting interpretations, forecasts, and policy conclusions all rested on very shaky ground, because the estimation of these linear systems generally relied on "incredible" identification assumptions.

To appreciate the problem of identification, suppose we consider the coffee market and try to explain movements in the quantity and price of coffee. A traditional approach is to isolate a variable that is believed to solely influence either supply or demand. One such variable is weather. Bad weather may reduce the amount of coffee produced at all prices, i.e., it shifts the supply curve inward. If the demand curve for coffee is not affected, a change in the weather will lower the equilibrium quantity of coffee and raise its price. Variations in weather therefore allow us to trace out - to identify - the shape of the demand curve. However, is the assumption that weather does not influence the demand curve plausible? Even if people's taste for coffee does not depend directly on the weather, as Sims pointed out coffee buyers know that weather is variable and may stock up when adverse weather variations arise. Thus, expectations about weather (and other varying determinants of supply and/or demand) are likely to affect both supply and demand, in such a way that weather changes may not have the expected consequences.

Even though it is well known that econometric identification is difficult in general, Sims (1980) highlighted specific problems in macroeconomics - 
mostly, but not only, in the context of monetary economics - owing to the expectations of consumers and firms. In particular, it is hard to find variables that only affect either demand or supply of some macroeconomic variable (such as consumption, or investment, or money), because expectations about macroeconomic outcomes are in all likelihood based on all available variables. Thus, identification in macroeconomic systems based on standard demandsupply arguments is unlikely to work.

Sims (1980) did not only criticize the predominant macroeconometric practice at the time. The paper also offered an identification strategy that relied on an entirely different logic than the estimation of large-scale Keynesian models. A leading idea is to exploit the fact that the solution to a macroeconomic system with active expectations formation can be expressed as a VAR. This VAR can then be used to explore different ways of identifying model parameters. Sims (1980) proposed a specific recursive scheme. A number of alternative VAR identification strategies have subsequently been proposed by Sims as well as by other researchers. Thus, by placing identification at the center of attention in macroeconomics, Sims's work made it a focal point of scientific discussion.

To illustrate how the proposed approach could be applied in practice, Sims (1980) estimated VARs for the U.S. and German economies, each based on quarterly time series for six macroeconomic variables (money, GNP, unemployment, wages, price level, and import prices). He then used the estimated and identified VAR-systems to analyze the dynamic effects of shocks, via impulse-response analysis and variance decomposition (see below).

Since this first paper, Sims has continued to push the frontiers of macroeconomic VAR analysis through methodological as well as substantive contributions. To give a few examples, Sims (1986) was one of the very first papers to discuss alternative identification schemes that are more structural than the recursive one applied in Sims (1980). Sims, Stock and Watson (1990) showed how to do estimation and inference in VAR systems with nonstationary time series, including the case of cointegrated series first analyzed by Engle and Granger (1987). Doan, Litterman and Sims (1986) was one of the crucial contributions to the forecasting with VARs estimated with Bayesian methods. Sims (1992) thoroughly discussed the effects of monetary policy on the macroeconomy, drawing on the results from six-variable VARs estimated on monthly time series for each one of the five largest economies.

According to Sims's view, VARs would be useful when interpreting time series, in forecasting, and for understanding the effects of policy changes. 
The ensuing literature confirms this most strongly for interpretation and forecasting. As for policy experiments, VARs have become a main tool of analysis for understanding the effects of temporary variations in policy but not - at least not yet - for analyzing long-lasting changes in policy.

\subsection{VAR analysis}

VAR analysis can be described in simple terms as a method for extracting structural macroeconomic shocks, such as unexpected exogenous shocks to the central bank's main policy instrument (e.g., the federal funds rate in the U.S.) or unexpected exogenous changes in productivity, from historical data and then analyzing their impact on the economy. Thus, this analysis is a tool for (i) estimation of a forecasting model, by separating unexpected movements in macroeconomic variables from expected movements; (ii) identification, by breaking down these unexpected movements into structural shocks, i.e., shocks that can be viewed as fundamental causes of macroeconomic fluctuations; (iii) impulse-response analysis, by tracing out the dynamic impact of these shocks on subsequent movements in all of the macroeconomic variables. These three steps in the procedure are described in the following subsections.

\subsubsection{The forecasting model}

Sims's VAR approach is typically based on linearity and a rather unrestricted specification with enough macroeconomic variables so that the system can capture the key dynamics of the macroeconomy. A prerequisite for the two remaining steps in the VAR method is a model that provides reasonable forecasts, which amounts to a built-in assumption that the agents in an economy (firms, households, etc.) make their forecasts actively, i.e., in a forward-looking manner and in response to how the economy develops over time.

Consider a vector $x$ of dimension $N$ denoting the macroeconomic variables of interest. Given this vector, a reduced-form vector autoregression of order $p$ is a process such that

$$
x_{t}=H_{1} x_{t-1}+\cdots+H_{P} x_{t-P}+u_{t},
$$

where $u_{t}$ is uncorrelated with $x_{s}, s \in\{t-1, \ldots, t-P\}$ and $E\left(u_{t} u_{t}^{\prime}\right)=V$. The idea is to chose $P$ large enough so that $u$ becomes uncorrelated over time. A 
large enough $p$ will allow the VAR to approximate any covariance-stationary process - thus, the specification in (1) is rather general. ${ }^{3}$

It is straightforward to identify $H_{p}, p=1, \ldots, P$ as well as the covariance matrix of the forecast errors $V$ using standard regression techniques. Specifically, the parameters $H_{p}$ can be estimated using ordinary least squares, equation by equation. Estimated in this way, the VAR can be used for forecasting. The shocks in (1), $u_{t}$, are forecast errors. They constitute differences between the realization of $x_{t}$ and the best forecast, given information on previous realizations of $x$. Thus, they are unpredictable.

Typically, these forecast errors for different components of $x_{t}$ are correlated with each other. Therefore, they cannot be regarded as fundamental, or structural, shocks to the economy. Instead, they should be viewed as a function - in practice, a linear combination - of these fundamental shocks. For example, suppose one of the variables in $x$ is the interest rate. Then, the corresponding element of $u_{t}$ cannot be interpreted as a pure interest-rate shock, unexpectedly engineered by the central bank. Specifically, part of the interest-rate forecast error may be due to other shocks if the central bank's interest rate responds to other variables in the system within a given quarter (a typical time period in macroeconomic models). Since policy variables tend to react systematically to macroeconomic developments, this qualification is very important. Thus, the system (1) cannot be used directly to infer how interest-rate shocks affect the economy. The breakdown of forecast errors into fundamental shocks is the identification part of VAR analysis to be discussed below.

Forecasting with VARs Even with a limited number of variables and without attempting to disentangle structural shocks from forecast errors, VARs can be used directly for forecasting. Such forecasting is now quite common. In a survey article, Stock and Watson (2001, p. 110) describe the state of the art as follows: "Small VARs like our three-variable system have become a benchmark against which new forecasting systems are judged." Forecasts with VARs have been compared with simple alternatives, such as forecasting based on univariate models or pure random walks, and have of-

\footnotetext{
${ }^{3}$ Nonstationary processes, and unit-root processes in particular, require separate analyses, but they can also be studied using VAR methods with appropriate transformations. This extension is related to the fundamental contributions of the 2003 laureate Clive W. J. Granger.
} 
ten been shown to outperform these techniques. Small VAR systems may not be entirely stable, however, and may thus not be stable predictors of future variables. As a result, state-of-the-art VAR forecasting tends to include more than three variables and allow for time-varying coefficients. The added generality quickly increases the number of parameters to be estimated. One common approach to this problem is to use BVARs, i.e., vector autoregressions estimated using a Bayesian prior (see Litterman, 1986 and Sims, 1993). Of course, the precise prior matters for the results, and many studies use the so-called Minnesota prior (Litterman, 1986, and Doan, Litterman, and Sims, 1986) or a variant thereof.

Nowadays, a new approach is gaining ground, where the prior is based on modern macroeconomic theory. That is, restrictions are formed based explicitly on how the econometrician a priori thinks the world works, expressed in the form of a model. Early examples of this approach include Del Negro and Schorfheide (2004). An alternative approach to forecasting is to rely on structurally estimated full (perhaps nonlinear) models, and how to judge the relative performance of different available forecasting approaches is still an open issue.

\subsubsection{Identification of structural shocks}

Denote the fundamental shocks hitting the economy at time $t$ by a vector $\varepsilon_{t}$, different from $u_{t}$. By definition, the components of vector $\varepsilon_{t}$ are independent variables, and their respective variances are normalized to unity. Like the elements of $u_{t}$, they are independent over time and therefore unpredictable. Moreover, by construction they can be viewed as exogenous shocks: the fundamental economic shocks which cause subsequent macroeconomic dynamics. Each element of the $\varepsilon_{t}$ vector therefore has an interpretation, such as an interest-rate rise generated by a surprise central-bank action, a sudden technology improvement, an unanticipated drop in oil prices, or an unexpected hike in government spending.

The mapping from structural shocks to forecast errors is assumed to be linear. ${ }^{4}$ Thus, we can write

$$
u_{t}=G \varepsilon_{t}, \quad \text { with } \quad G G^{\prime}=V
$$

\footnotetext{
${ }^{4}$ Linearity is not a necessary component of the specification but greatly simplifies the analysis.
} 
where $V$ is a variance-covariance matrix. The identification task now is to impose appropriate restrictions on $G$. This requires knowledge of how the economy works and a method for making use of such knowledge. Some of the main identification schemes are briefly discussed below.

Recursive identification The most common identification method, and the one Sims $(1980,1989)$ used, is a so-called recursive scheme. The idea here is to order the elements of $x$ in such a way that the $G$ matrix can plausibly be argued to be lower triangular. In a simple three-variable case, this would amount to a matrix of the form

$$
G=\left[\begin{array}{ccc}
g_{11} & 0 & 0 \\
g_{21} & g_{22} & 0 \\
g_{31} & g_{32} & g_{33}
\end{array}\right]
$$

It is necessary to determine the order of the variables. In the example, variable 1 does not respond to the fundamental shocks in the other variables 2 and 3, variable 2 responds to shocks in variable 1 but not to shocks in variable 3 , and variable 3 responds to shocks in both of the other variables. The ordering assumed is based on how rapidly different variables can react. For example, it may be argued that most shocks cannot influence government spending contemporaneously (if the time period is short, such as a quarter or a month), as most government activity is planned in advance and implemented rather sluggishly. Stock prices, on the other hand, move very quickly and are arguably influenced by shocks to all contemporaneous variables, even within a short time period.

In terms of this type of discussion, recursive identification is based on economic theory, but only in a rudimentary sense. It is sufficient to understand how economic variables are defined and what decisions lie behind them, without needing a specific structural theory of exactly how the variables are linked. Therefore, recursive identification may often be more robust and credible than identification schemes that rely on more detailed theoretical assumptions of how the economy works. In "partial" recursive identification, only a partial ordering is used, whereby some shocks can be identified and others cannot. This method may be practical when an a priori ordering of all variables in a larger system is difficult, and the focus is on a small set of shocks, such as the monetary policy shocks. See, e.g., Sims and Zha (2006) for such an approach. 
Given an ordering, the elements of $G$ can easily be computed from an estimate of $V$ (assuming that the estimate $\widehat{V}$ is positive definite). Recursive identification amounts to a particular way of decomposing the matrix $V$, which is called a Cholesky decomposition. ${ }^{5}$ If the variables can convincingly be ordered on a priori grounds in this manner, the identification task is solved.

Other schemes for identification An alternative and more structural scheme is "long-run identification", first proposed by Blanchard and Quah (1989). Here, economic theory is used to make assumptions about which shocks affect the economy in the long run. Blanchard and Quah took the view that Keynesian-style demand shocks have no effect on output in the long run, even though they may certainly influence output in the short run. But other shocks - like technological or institutional change - do exercise a potential influence on long-run output. Formally, the long-run shock variance of the $x$ vector would be expressed as a function of the individual shocks $\varepsilon_{t}$ by iterating forward using the VAR system (1). Restricting one element in the matrix of long-run variances to zero amounts to an identifying assumption. Other early approaches to structural identification include Bernanke (1986) and Sims (1986).

Still other identification schemes may combine short-run and long-run restrictions. They may also involve more elaborate assumptions from theory. One approach followed by Faust (1998), Canova and De Nicolò (2002) and Uhlig (2005) is to use mild assumptions in the form of "sign restrictions". Here, certain (usually short-run) impulses or cross-correlations are assumed to have a certain sign, whereas others are left unrestricted. Even if such restrictions may not pin down the $G$ matrix uniquely, they may still rule out many possibilities. For example, the assumption that positive interest-rate shocks cannot raise contemporaneous inflation implies that such shocks must lower contemporaneous output - not by a determinate magnitude but in a qualitative sense.

The usefulness of sign restrictions and agnostic identification depends on the context. Consider an example (the one used later in Section 3) with three variables - inflation, output, and the interest rate - where each variable has a contemporaneous influence on every variable. A recursive identification scheme is not consistent with this structure, since no variable is influenced

\footnotetext{
${ }^{5}$ The Cholesky decomposition, for a given ordering of variables, is unique.
} 
only by its own structural shock, or by only two structural shocks. But the structural shocks can still be consistently identified by sign restrictions and agnostic procedures, since these rely precisely on theoretical restrictions on how different variables are interrelated.

VAR identification based on classes of structural models rather than on a very specific structure is common in applied work and a very active research area. This research has led to a series of new "stylized facts" on how the macroeconomy behaves, some of which are briefly described in the context of the monetary-policy example in Section 3.

\subsubsection{Impulse-response analysis}

With the structural shocks in hand, one can proceed to another central element of VAR methodology: impulse-response analysis. An impulse-response function describes how a given structural shock affects an element of the $x$ vector over time: the impulse (cause) and its propagation (effect).

It is straightforward to obtain the impulse responses from a VAR representation. Using $L$ to denote the lag operator (i.e., $L^{p} x_{t} \equiv x_{t-p}$ ), the structural version of the VAR in (1) becomes

$$
x_{t}=\left[I-H_{1} L-H_{2} L^{2}-\cdots-H_{P} L^{P}\right]^{-1} G \varepsilon_{t} .
$$

In other words, $x_{t}$ can be described solely in terms of the entire history of structural shocks. At the same time, the weight on $L^{p}$ in the square brackets reflects how a shock at $t-p$ influences $x_{t}$. An impulse response is thus obtained by inspecting - typically in a plot - how the $H$ elements of this sum vary with $p$.

The estimation of VAR coefficients and their accompanying standard errors is rather straightforward. But providing error bands and confidence intervals for impulse-response functions is more complicated, and in the early days of VAR analysis, error bands were not always provided. Nowadays, however, they are routinely computed and displayed. Sims's own approach, along with a significant part of the literature, is to use Bayesian methods, but it is also common to provide classical confidence intervals.

Impulse-response analysis has also become a very valuable tool for comparing models with data. This approach was initiated in Sims (1989). Since estimated impulse responses provide "stylized facts" of a new variety, those who formulate theoretical models of the macroeconomy commonly simulate the model counterparts of estimated impulse responses. In developing new 
models, common impulse-response estimates from the VAR literature are thus used as reference points.

Another common element of the VAR methodology - closely related to impulse-response analysis - is to perform so-called variance decomposition. This amounts to computing how large a share of the variance of each variable at different time horizons is explained by different types of structural shocks. Thus, it may be concluded how different shocks have different effects at different horizons but combined account for the full dynamics of the macroeconomic variables.

\subsubsection{VAR applications}

VAR analysis is used in a very broad set of contexts, including areas outside macroeconomics such as financial economics. Some of the macroeconomic applications are as follows.

What are the effects of monetary policy? VARs have arguably been most important in monetary economics. In particular, VARs have been used to establish a set of facts regarding the effects of monetary policy. Monetary shocks - changes in the interest rate controlled by the central bank (the federal funds rate in the U.S., or the fixed repo rate in the Euro area) have a significant impact on both monetary and real variables, even though these effects appear rather slowly and tend to display a hump-shaped pattern; see the example in Section 3. As mentioned above, Sims (1992) discussed the effects of monetary policy across five different economies, finding several common features but also some differences.

What are the effects of fiscal policy? In the recent 2008-2009 recession, a central question for policymakers concerned the economy's response to temporary government spending (or temporary tax cuts). This is a complex issue and clearly a reasonable answer should involve how, say, a spending increase comes about (how it is financed), as well as what kind of spending is raised. But are there any general lessons to be learned from looking at historical data? As in the other contexts discussed so far, it is very important here to separate expected and unexpected changes, i.e., structural (endogenous) shocks and (endogenous) responses, in government spending. Various methods have been proposed to achieve this. One is to consider military spending, which arguably has an important exogenous component. 
Another is the so-called narrative approach, pioneered in Romer and Romer (1989). However, some of the most commonly cited studies employ a VAR methodology to identify how the economy reacts to spending. This is the case in an influential study by Blanchard and Perotti (2002), who formulate a VAR with three variables: government spending, taxes, and output. Their identification relies on knowledge of how total taxes react to changes in income for a given tax schedule, while leaving other changes to be interpreted as fundamental fiscal policy shocks. Blanchard and Perotti's estimates imply that positive government spending shocks and negative tax shocks influence output positively, with economically significant effects. The sizes of these responses (often labeled fiscal multipliers) have since been the subject of extensive recent research with VAR methods.

What causes business cycles? Another important set of results obtained through the use of VARs concerns the perennial question as to what drives business cycles. In particular, researchers have used VAR methods to examine Kydland and Prescott's arguments that technology (productivity) movements are essential drivers. Using a variety of identification schemes, technology shocks have been compared to other shocks such as monetary policy shocks. Sims's own first studies on this topic, in particular his 1972 paper "Money, Income, and Causality", had an important impact. He found that monetary movements cause movements in income (money "Grangercauses" income), in the sense of Granger (1969), thus lending some support to a monetarist view. ${ }^{6}$ However, variance decomposition shows that a rather small fraction of the total movements in output are accounted for in this way, especially in the longer run. This has given rise to a large and active subsequent literature, with studies inspired by both real-business-cycle theories and Keynesian theories.

Along these lines, Galí (1999) examined technology shocks versus other shocks through a VAR analysis, based on long-run restrictions for identification. In a very simple $2 \times 2$ VAR with productivity and total hours worked, Galí reached the conclusion that technology shocks have relatively limited, and somewhat counterintuitive, short-run impacts. This has been followed by many other studies and has generated a debate that is still in progress,

\footnotetext{
${ }^{6}$ Heuristically, a variable $x$ Granger-causes another variable $y$ if information about the prior realizations of $x$ makes it possible to arrive at better forecasts of future realizations of $y$ than if only past realizations of $y$ were observed.
} 
since it represents an alternative method for calibrating models when comparing central theories of business-cycle fluctuations. The identification of technology shocks - which are arguably hard to measure directly - through long-run identifying restrictions based on VAR models has become an important subfield in recent empirical business-cycle analysis.

\section{An Example: Monetary Policy and Macro- economic Activity}

In order to illustrate the methods developed by Sargent and Sims, let us introduce a simple but commonly studied three-variable models of the macroeconomy, with inflation, output, and the nominal interest rate. The interest rate represents the monetary-policy variable whereas inflation and output are determined by the private agents in the economy - households and firms. First, we use this simple description of the economy to illustrate how identification of monetary policy shocks is usually performed with the VAR methodology developed by Sims. Impulse-response analysis then allows us to trace the dynamic effects of unexpected changes in the interest rate engineered by the monetary authority. Second, we use Sargent's approach to describe the analysis of a change in the policy regime, i.e., a systematically different way of choosing the interest rate. This requires us to formulate a more elaborate model of the economy in which structural estimation can be applied to identify deep, policy-invariant parameters. The structural model can then be used as a laboratory for assessing different interest-setting rules. The example in this section also illustrates how the methods of Sargent and Sims relate to each other.

\subsection{A monetary VAR analysis}

Let us now follow the three-step method developed by Sims, letting the VAR be

$$
\left(\begin{array}{l}
\pi_{t} \\
y_{t} \\
i_{t}
\end{array}\right)=F\left(\begin{array}{l}
\pi_{t-1} \\
y_{t-1} \\
i_{t-1}
\end{array}\right)+\left(\begin{array}{l}
u_{\pi, t} \\
u_{y, t} \\
u_{i, t}
\end{array}\right),
$$

where $\pi$ is the inflation rate, $y$ output, and $i$ the nominal interest rate. Consider all of these variables as departures from trend: output, for example, 
really stands for the output gap, a measure of capacity utilization. ${ }^{7}$ In practice, VARs rely on a number of lags, but here we adhere to a single lag to economize on notation.

As explained in Section 2.2 above, the VAR constitutes a forecasting system that can be estimated using standard methods based on historical data. The time series of errors obtained, the vector $u_{t}$, is therefore unpredictable by construction. It is a prediction error, but does not reveal the fundamental shocks to the economy. In particular, $u_{i}$ cannot be interpreted as exogenous, or central-bank-engineered, shocks to the interest rate.

Then, how are the fundamental shocks identified? The ordering of the variables in the system above reflects recursive identification, commonly used in the monetary literature. The assumptions are thus: (i) a current shock to inflation is the only structural shock that influences inflation contemporaneously; (ii) contemporaneous output is affected by the inflation shock as well as an output shock; (iii) the interest rate can respond to all three fundamental shocks in the system, including the fundamental shock to the interest rate itself. Although rather stringent, these assumptions are usually viewed as reasonable by applied macroeconomic researchers when the data are monthly (or even quarterly). Concretely, the assumptions may reflect the inherent relative sluggishness of the different variables, due to informational differences among different actors in the economy, as well as adjustment costs. The assumptions give us

$$
\left(\begin{array}{l}
u_{\pi_{t}} \\
u_{y_{t}} \\
u_{i_{t}}
\end{array}\right)=G\left(\begin{array}{l}
\varepsilon_{\pi_{t-1}} \\
\varepsilon_{y_{t-1}} \\
\varepsilon_{i_{t-1}}
\end{array}\right),
$$

where $\varepsilon$ is the vector of structural shocks and $G$ has the diagonal structure described in equation (2). Since $G$ is invertible, it is easy to compute the structural shocks from the forecast errors obtained in the VAR estimation. The $G$ matrix is obtained uniquely from the relation $V=G^{\prime} G$, since this matrix equation amounts to six equations in six unknowns.

What do the estimated time series of monetary policy shocks imply in practice? As an example, let us consider the results reported in a study of

\footnotetext{
${ }^{7}$ Despite measuring the three variables as deviations from trend, some of them may still not be stationary in applications. Among others, the 2003 economics laureate Clive Granger has shown how non-stationary variables can be handled in VAR models. On this, see also Sims, Stock and Watson (1990).
} 
the U.S. economy by Christiano, Eichenbaum, and Evans (1999). This study, which relies on recursive identification in a medium-scale VAR model, fits our illustration because it focuses on output, inflation and interest rates. It is also appropriate in that the authors make an explicit connection to a structural macroeconomic model, which is an extended version of the model discussed below. The Christiano-Eichenbaum-Evans study derives time paths for the key macroeconomic shocks and variables that are reasonably robust to the identification scheme. The patterns, moreover, appear quite similar across different countries.

A selection of estimated impulse-response functions is depicted in Figure 2, which shows how an increase in the federal-funds rate affects U.S. output and inflation. The top graph shows how an increase (by one standard deviation) in the short-run interest rate gradually fades away, over approximately six quarters. Such a shock leads to a smooth hump-shaped output contraction (the middle graph), no immediate response for inflation but a delayed decrease in the price level (the bottom graph). These responses are entirely "conditional" and can be viewed as constituting an event study, where the event is an unanticipated increase in the short-run interest rate by the central bank.

Findings such as those in Figure 2 underlie the common practice by inflation-targeting central banks of setting their interest rate with a view to inflation one to two years down the line. As can be seen from the bottom graph, a current interest-rate shock has little effect on inflation in the first four quarters. The results also suggest a clear tradeoff in the pursuit of contractionary monetary policy: gains in terms of lower future inflation have to be weighed against losses in terms of lower output in the more immediate future. Analogously, expansionary interest-rate policy has to trade off higher output in the immediate future against higher inflation in the more distant future. 

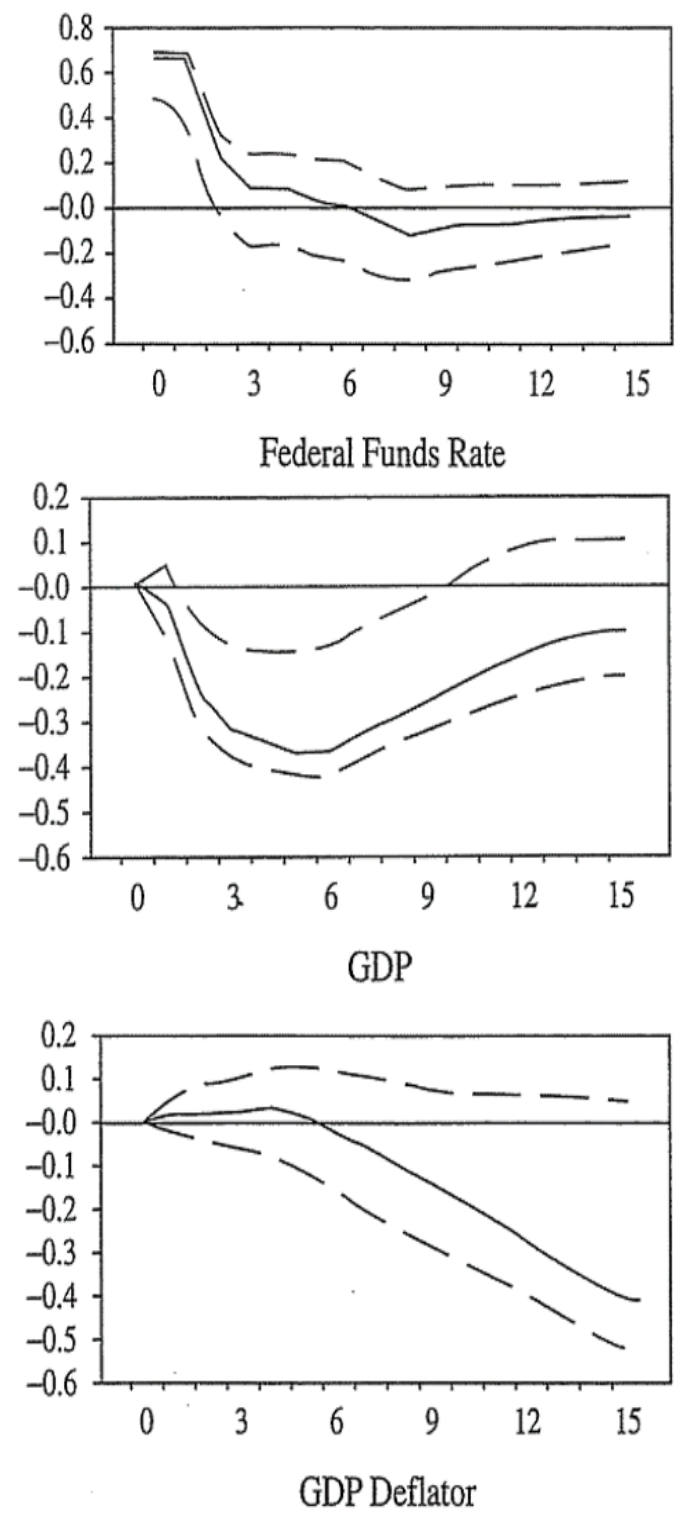

Figure 2: Estimated dynamic response to a monetary policy shock. The y axes display percentage response of the interest rate, output, and the price level, respectively, to a one-standard-deviation (0.72 point) increase in the Fed funds rate, while the axes display quarters. Source: Christiano, Eichenbaum and Evans (1999). 
Findings such as those in Figure 2 have also been used extensively in the development of new macroeconomic theories. Any new theory of monetary and real variables has to be capable of reproducing the VAR evidence. The connection between theory and empirics has implied that theories are often studied in their (approximate) VAR representations, since this allows for easy comparison with empirical VAR studies.

\subsection{Analysis of changes in the monetary policy regime}

After having arrived at estimates of historical unexpected changes in monetary policy and their subsequent impact on the economy, the harder question remains how systematic changes in monetary policy would alter the dynamic behavior of inflation, output, and the interest rate. The inherent challenge is that such policy changes would likely influence the estimated VAR coefficients ( $F$ and $V$ ), since the workings of the economy - in particular households' and firms' expectations of future policy - will be altered. This is where Sargent's method of structural estimation is required. By specifying how the economy works in more detail, the method allows us to disentangle exactly how the VAR coefficients will change.

Consider a simple structural model of the economy. To keep matters as simple as possible, the coefficients in the model example are not derived from microeconomic foundations, although examples of such derivations are hinted at in footnotes below.

Model formulation Maintaining the earlier notation, the nominal side of the private economy is described by an equation that determines the path of inflation:

$$
\pi_{t}=a_{E \pi} E_{t} \pi_{t+1}+a_{\pi} \pi_{t-1}+a_{y} y_{t}+\varepsilon_{\pi, t} .
$$

The first term on the right-hand side captures the forward-looking aspect of price formation $-E_{t} z_{t+1}$ denotes the private sector's expectations, at $t$, of any variable $z_{t+1} .8$ Including inflation expectations in this equation may reflect forward-looking price setting by individual firms, for example, because they may not change their prices in every time period and therefore care about future demand conditions and the prices of other firms. The second term captures a backward-looking component of inflation, for instance due to indexation of contracts. The output gap, $y$, also influences prices (the third

\footnotetext{
${ }^{8}$ For simplicity, this and the following equations are shown without constants.
} 
term), typically because high output is associated with higher marginal costs of production. Finally, $\varepsilon_{\pi}$ is an exogenous (often called cost-push) shock, i.e., a random variable. ${ }^{9}$

In the second equation of the model, output is determined by

$$
y_{t}=\left(1-b_{y}\right) E_{t} y_{t+1}+b_{y} y_{t-1}+b_{r}\left(i_{t}-E_{t} \pi_{t+1}\right)+\varepsilon_{y, t} .
$$

The first term in the expected output (gap) appears because output, similar to prices, is partly determined in a forward-looking way. This may capture smoothing over time, especially of consumption. The second, backwardlooking term (with $b_{y}>0$ ) may be due to adjustment costs or habits in consumer preferences. According to the third term, output reacts negatively to a higher real interest rate $\left(b_{r}<0\right) ; i$ is the nominal interest rate and $i-E \pi$ is the real interest rate. The idea here is that a high real interest rate makes current consumption less attractive relative to future consumption. Output also contains a random element $\varepsilon_{y}$, for example reflecting fluctuations in consumers' attitudes toward saving. ${ }^{10}$

\footnotetext{
${ }^{9}$ To give a hint regarding the microeconomic foundations of (3), suppose firms are monopolistic competitors - each sells one out of a variety of imperfectly substitutable consumption goods. Their production function includes a random labor-augmenting technology component, is common across goods, and has decreasing returns to labor input. Several models of price stickiness imply Phillips-curve relations as in equation (3). For instance, suppose that in its price setting, each firm is able to adjust its price with probability $1-\theta$, but when a price adjustment is possible, it is entirely forward-looking and maximizes the expected present value of profits (this setting relies on Calvo, 1983). Then, a version of equation (3) - with $a_{\pi}=0$ - holds as a linearization around a zero-inflation steady state, where $\pi$ is the appropriate aggregate price index for the variety of consumption goods. In this case, the parameters of the equation $-a_{E \pi}$ and $a_{y}$ - can be written as explicit functions of underlying primitives $\beta, \alpha, \gamma$, and $\theta$, where $\beta$ represents the consumer's subjective discount factor (which is used in the firm's present-value calculation), $\alpha$ the elasticity of output with respect to labor input, and $\gamma$ the contemporaneous elasticity of substitution across the different consumption goods. The case where $a_{\pi} \neq 0$ refers to a more elaborate setting, either with a more complex adjustment assumption for prices or an assumption that some price contracts are indexed to inflation. The shock $\varepsilon_{\pi}$ can represent exogenous movements in the firm's price markup over marginal costs.

${ }^{10}$ Ignoring the taste shock and setting $b_{y}=0$, equation (4) can easily be derived from the representative consumer's optimal-saving condition. This so-called Euler equation sets the marginal utility value of consumption today equal to the discounted value of consumption tomorrow times the return on saving: $u^{\prime}\left(c_{t}\right)=\beta E_{t}\left[u^{\prime}\left(c_{t+1}\right)\left(\frac{1+i_{t}}{1+\pi_{t+1}}\right)\right]$. Here, $u$ is the utility function and $\frac{1+i_{t}}{1+\pi_{t+1}}$ the realized gross real interest rate between $t$ and $t+1$, and $\beta$ is the consumer's discount factor. With a power utility function, $u(c)=c^{1-\sigma} /(1-\sigma)$,
} 
The simple model economy is completed with a common specification of policy, where the central bank sets the nominal interest rate according to a form of the "Taylor rule":

$$
i_{t}=c_{\pi} \pi_{t}+c_{y} y_{t}+c_{i} i_{t-1}+\varepsilon_{i, t},
$$

where $\varepsilon_{i}$ is a monetary policy shock. The three response coefficients in the policy rule are all positive: $c_{\pi}>0$ means that the central bank raises the interest rate when inflation goes up, $c_{y}>0$ that it raises the interest rate in the wake of higher output, and $c_{i} \geq 0$ that it prefers smooth changes in interest rates.

To describe macroeconomic fluctuations, suppose that all parameters of the model - the coefficient vectors $a, b$, and $c$ - are given. Random $\varepsilon$ shocks are realized over time, thereby causing fluctuations in output and inflation as well as in monetary policy. In the example, the $c$ coefficients are policy parameters, while the $a$ and $b$ coefficients reflect deep microeconomic parameters in preferences, technology, and other policy-invariant details of the environment. As suggested in footnotes 9 and 10, these coefficients may depend on a small number of such parameters. The $\varepsilon$ vector is assumed to be unpredictable.

It may seem intuitively clear that a change in the policy rule of the monetary authority - say, an increased sensitivity of the interest rate to the inflation rate, a higher value of $a_{\pi}$ - will influence the time-series properties of the economy. But how exactly? The difficulty in analyzing this economy over time is that current events depend on expectations about the future, at least if $E_{t}$ reflects some amount of forward-looking, purposeful behavior, i.e., knowledge of how the economy works. For example, if private firms at $t$ form expectations of prices at $t+1$ and expect the price formation equation to hold also at $t+1$, their expectations should reflect that knowledge. In this example, rational expectations mean precisely that expectations are formed with full knowledge of equations (3)-(5). Events at $t$ thus depend on events

$\sigma$ governing the intertemporal elasticity of substitution in consumption, one can linearize the logarithm of the Euler equation. Since consumption must equal output in a closed economy without investment, the real interest rate has to be set so that saving equals zero. This condition implies equation (4). In this way, $b_{r}$ in equation (4) can be derived as a function of $\sigma$. As for the second term in (4), one obtains $b_{y} \neq 0$ if the utility function has a form of consumption habits, where past consumption influences current utility. The first two coefficients, $1-b_{y}$ and $b_{y}$, sums to unity due to an assumption that the utility is jointly homothetic in current and past consumption. 
at $t+1$, which in turn depend on events at $t+2$, and so on. Prior to the rational-expectations literature, expectations were treated as exogenous or mechanically related to past values. For example, expected inflation could be assumed constant or equal to current inflation. This meant that it was an easy, mechanical, task to find a solution to an equation system like (3)-(5). But the underlying assumption was that a change in the policy regime did not trigger any response of private-sector expectations. This was clearly an incredible assumption, especially in the case of monetary policy.

Model solution and cross-equation restrictions How did Sargent proceed in solving such a system? ${ }^{11}$ An important first step was to generally characterize the solution to a typical macroeconomic model of this sort. In early contributions, Sargent $(1977,1978 \mathrm{a}, 1978 \mathrm{~b})$ used the fact that the structure of equations such as (3)-(5) allowed a "forward" solution. Sargent thus expressed current variables as a(n infinite) weighted sum of current and expected future shocks $\varepsilon$ and predetermined variables $\pi_{t-1}, y_{t-1}$ and $i_{t-1}$ with weights that all depend on the primitive parameter vectors $a, b$, and $c$. As a second step, given explicit assumptions on the distributions for the shocks - for instance, that they be normally distributed - he appealed to the statistical time-series literature, which shows how general processes of this kind can be estimated using maximum-likelihood methods. The goal here was to estimate the vectors $a, b$, and $c$, the deeper determinants of the general timeseries process for $i, \pi$, and $y$. Sargent showed that this could be accomplished in a relatively straightforward way. ${ }^{12}$

A key insight here is that the structural parameters appear in different equations of the system and thus imply cross-equation restrictions. Sargent called these restrictions the "hallmark" of rational-expectations econometrics and such restrictions are still central elements of modern estimation. Sargent also used recursive methods for linear macroeconomic systems of the type described in equations (1)-(3).

To illustrate the method and compactly show how cross-equation restrictions appear, it is useful to use a recursive representation. Conjecture that

\footnotetext{
${ }^{11}$ To be clear, Sargent did not solve and estimate the model in this particular example.

${ }^{12}$ In terms of the parameters of utility and technology discussed in footnotes 9 and 10 , the goal was to estimate $\alpha, \beta, \gamma, \sigma$, and $\theta$.
} 
the solution to equations (1)-(3) for all $t$ would take the form

$$
\left[\begin{array}{c}
\pi_{t} \\
y_{t} \\
i_{t}
\end{array}\right]=F\left[\begin{array}{c}
\pi_{t-1} \\
y_{t-1} \\
i_{t-1}
\end{array}\right]+G\left[\begin{array}{l}
\varepsilon_{\pi, t} \\
\varepsilon_{y, t} \\
\varepsilon_{i, t}
\end{array}\right]
$$

where $F$ and $G$ are $3 \times 3$ matrixes. As before, the components of matrix $F$ and the stochastic properties of the residual $G \varepsilon$ can readily be estimated by standard regression methods.

However, the task at hand is not to estimate the $F$ and $G$ matrices, but instead the basic parameter vectors $a, b$, and $c$. This requires finding the mapping between the two. Using $x_{t}$ to denote $\left[\begin{array}{lll}y_{t} & \pi_{t} & i_{t}\end{array}\right]^{\prime}$ and $\varepsilon_{t}$ to denote $\left[\begin{array}{lll}\varepsilon_{y, t} & \varepsilon_{\pi, t} & \varepsilon_{i, t}\end{array}\right]^{\prime},(6)$ becomes $x_{t}=F x_{t-1}+G \varepsilon_{t}$. Moreover, the structural equations (3)-(5) can be written as $x_{t}=A x_{t}+B E_{t} x_{t+1}+C x_{t-1}+\varepsilon_{t} .{ }^{13}$ Given the conjectured solution, it must be the case that $E_{t} x_{t+1}=F x_{t}$, since the shock vector $\varepsilon$ is unpredictable. This implies $x_{t}=A x_{t}+B F x_{t}+C x_{t-1}+\varepsilon_{t}$. Assuming that $I-A-B F$ is invertible, we must have

$$
x_{t}=[I-A-B F]^{-1} C x_{t-1}+[I-A-B F]^{-1} \varepsilon_{t} .
$$

Thus, the conjectured solution is verified with $[I-A-B F]^{-1} C=F$. This is indeed a cross-equation restriction, where the fundamental parameters in $A$ and $B$ imply restrictions on the coefficients in matrix $F$.

When estimating an equation like $x_{t}=F x_{t-1}+u_{t}$, where $u$ is a regression residual, it is necessary to recognize the restrictions which theory imposes on the coefficients in the $F$ matrix. In the model example, this restriction involves nine equations in eight unknown parameters (contained in $A, B$, and $C$ ). Moreover, residual $G \varepsilon$ has a variance-covariance matrix with six distinct elements, which gives six additional equations through $G G^{\prime}=[I-A-B F]^{-1}\left([I-A-B F]^{-1}\right)^{\prime}$. The variance-covariance matrix of $\varepsilon$ has three distinct elements - since the three shocks are stochastically independent - which adds three fundamental parameters to be estimated. In total, the simple example has 15 equations and 11 unknown parameters. Thus, the system is over-identified as long as certain conditions are met. ${ }^{14}$ It

$$
{ }^{13} \text { Here, } A=\left[\begin{array}{ccc}
0 & a_{y} & 0 \\
0 & 0 & b_{r} \\
c_{\pi} & c_{y} & 0
\end{array}\right], \quad B=\left[\begin{array}{ccc}
a_{E \pi} & 0 & 0 \\
-b_{r} & 1 & 0 \\
0 & 0 & 0
\end{array}\right] \text { and } C=\left[\begin{array}{ccc}
a_{\pi} & 0 & 0 \\
0 & b_{y} & 0 \\
0 & 0 & c_{i}
\end{array}\right] \text {. }
$$

${ }^{14}$ These conditions involve local invertibility of the mapping between the $(F, G)$ and the $(A, B, C)$ matrices. 
can be estimated using maximum likelihood, and the cross-equation restrictions implied by the model can be tested explicitly by an over-identification test. Given parameter estimates, (estimates of) the fundamental shocks $\varepsilon$ are recovered.

Note also that the new equation system (6) is written as an autoregression in vector form: it is a VAR. This insight extends quite generally in the sense that structural models have VAR representations. ${ }^{15}$ In the example, we can translate the structural model into a VAR, using $[I-A-B F]^{-1}$ to map the true innovations $\varepsilon$ to the VAR residual $u$. The identification problem, in the case of the structural model, is precisely to find "the right $G$ " or, equivalently, to find $A, B$, and $F$. Owing to this, finding the structural shocks in the VAR is closely related to finding the deep parameters of the system in (3)-(5). Clearly, if we manage to find $A, B$, and $F$, the identification problem of finding the fundamental shocks $\varepsilon$ is solved. Thus, there is a tight connection between finding the fundamental shocks in the VAR and finding the deep parameters of the system in (3)-(5).

Viewed in this light, Sargent's method involved imposing a specific economic model, including well-defined dynamics - in the example, how the lagged terms appear - and then structurally estimating that particular model. Sims's proposed method is an alternative: rely less on a specific model formulation and instead rely on a whole class of statistical models. Whereas Sargent's method requires a convincing model of the economy, Sims's method requires a convincing identification scheme.

In many macroeconomic models of current interest, the original microeconomically founded equations are non-linear rather than linear. This makes the cross-equation restrictions harder to characterize, and the estimation harder to carry out than in the simple linear example above. Moreover, modern estimation is not always carried out using classical maximum likelihood methods but rather by Bayesian techniques. Despite these complications, the central insights from Sargent's work continue to guide empirical work today.

\footnotetext{
${ }^{15}$ In terms of the specific identification method used by Christiano, Eichenbaum, and Evans (1999), recursive identification is not consistent with the simple structural model in our example. As expectations operators appear on the right-hand side of the equations, there are no zeroes in the $G$ matrix. The authors argue, however, that although expectations are crucial determinants of economic activity, all economic participants do not have the same information. By spelling out such informational differences, they show how recursive identification of the sort shown above is fully consistent with this extension of the model.
} 
Different types of policy analysis In the model discussed above, one can evaluate the effects of monetary policy in two different ways. One way would be to consider the effects of temporary policy shocks, in the sense of specific realizations of $\varepsilon_{i, t}$ - random shocks, so-called control errors, to the interest rate - for a given policy rule (i.e., for given coefficients $a_{i}, a_{\pi}$, and $a_{y}$ ). Policy analysis with the VAR methodology is the study of such policy shocks, i.e., unexpected (by the private sector) movements in the short-term nominal interest rate controlled by the central bank. Impulse-response diagrams are then used to trace the immediate and future impacts of a policy shock on macroeconomic variables.

The other way to evaluate monetary policy is to consider changes in policy regimes, i.e., lasting changes in the systematic reaction of policy to economic variables. After having structurally estimated the model economy and solved for structural parameter vectors $a$ and $b$, one may conduct counterfactual policy experiments by varying the coefficient vector $c$. Specifically, once the deep parameters in $a$ and $b$ have been identified, they are held constant as $c$ varies. However, the reduced form defined by $F$ and $G$, which describes the data, will indeed vary since these matrixes do indeed depend on $c$. This is the essence of the celebrated Lucas critique (1976). ${ }^{16}$ According to the estimation procedure sketched above, these variations in $F$ and $G$ are clear and predictable, as they arise only through the well-defined effects of $c$ on the reduced form. This implies that experiments, comparing different policy regimes, can be performed in a way that is immune to the Lucas critique.

The structural macroeconometric approach to policy analysis and the VAR approach were developed in parallel and reflect different views on government versus the private sector. Sims's view considers policy shocks as deliberate actions, which are unpredictable by the private sector; see Sims (1987). In other words, the information sets of the central bank and the private sector do not coincide. Policy shocks can thus be seen as deliberate actions from the perspective of the central bank, yet unpredictable from the perspective of the private sector.

Questions regarding the public's view of monetary policy and the Federal Reserve's view of the workings of the U.S. economy have been addressed in

\footnotetext{
${ }^{16}$ In words, Lucas's point was that the researcher cannot hope to analyze policy experiments if the equations describing the economy $(F$ and $G$ ) are taken as unaffected by policy $(c)$ when they actually are. The solution is thus to identify deeper, policy-robust parameters $(a$ and $b)$ that in turn, along with policy, determine the equations of the economy.
} 
recent related contributions by both Sargent and Sims. As mentioned above, Sargent, Williams, and Zha (2006) explicitly model central-bank learning in this process, and tentatively conclude that monetary policy in the 1970s was based on a temporary belief about the Phillips curve which was later revised. ${ }^{17}$ Sims and Zha (2006), on the other hand, formally estimate a regime-switching model and find some evidence of a policy switch, but only in terms of shock variances and not in terms of the nature of policy. Despite vigorous research in this area, these important issues have not yet been fully settled.

\section{Other Contributions by Sargent and Sims}

Sargent and Sims have continued their research on the interaction between money and economic activity. Both scholars have preserved in placing special emphasis on how expectations are formed. These contributions are briefly described below. Sargent and Sims have also made other important contributions to macroeconomics, broadly defined, which are not covered here.

Sargent and robust control Over the last decade, joint research by Lars P. Hansen and Sargent has explored an approach to decisionmaking and expectations formation known as robust control theory (see, e.g., their 2008 monograph Robustness). This approach assumes that households and firms act under strong aversion to uncertainty about the "true model" of the economy and adds a new dimension to expectations formation. Following the engineering literature, the central idea is that decisionmakers are not only averse to risk, but also do not know the true stochastic process which generates uncertainty. Moreover, they are very cautious and act as if they are playing a game with "nature" which systematically tries to harm them.

Formally, the decisionmaker solves a maxmin problem, i.e., maximizes his objective (the "max" part) under the assumption that nature selects the outcome that is worst for him (the "min" part). Such behavior reflects caution in that it guarantees a high lower bound on the solution. Expectations about the future are no longer those dictated by objective uncertainty - rational expectations - but rather embody a degree of pessimism.

An interpretation of robust control theory in economics is that households

\footnotetext{
${ }^{17}$ A similar approach is followed in Primiceri (2006).
} 
and firms may not "know the model", i.e., they do not fully understand what processes generate the uncertainty in their economic environment. In this sense, Sargent and Hansen's new research program exploits a form of bounded rationality, albeit with agents who exhibit a high degree of sophistication, since they are still able to solve complex problems.

Sims and rational inattention An alternative approach to rational expectations formation is to directly model agents' capacity constraints on information processing. This approach, labeled rational inattention, was initiated in Sims (2003, 2006). It relates to earlier literature in financial economics where all market participants may not have the same information. In the finance literature, this is most often modeled as different agents receiving different information signals. Owing to signal-extraction conditions and certain incompleteness of markets, all information is not revealed and spread through market prices (see Grossman and Stiglitz, 1980).

Rational inattention can potentially explain how different agents might act on different information sets. It is not that they cannot access the information, but that it is costly to interpret it. Sims imports the formal concept of Shannon capacity from information theory and shows how agents optimally choose the nature of the signals they will receive and upon which they subsequently will act. More informative signals allow better decisions but are also more costly, and agents have a limited amount of processing capacity available for different tasks. Thus, even if information is abundant, agents are restricted by their ability to interpret and act on information.

This research program suggests that rational inattention can produce sluggish movements in both prices and quantities, something which is observed in most contexts, as in the VARs discussed above. Earlier models, based on various kinds of adjustment costs, could generate sluggishness but then either for prices alone or for quantities alone. Another interesting insight in this context is that optimizing price-setting sellers may not choose prices on a continuous scale. They may instead select prices from a discrete set, because this allows efficient information processing for buyers, or because the sellers themselves face information-processing constraints. The literature on rational inattention offers a novel perspective on expectations formation and is attracting increasing interest. 


\section{Conclusion}

Thomas J. Sargent and Christopher A. Sims developed the methods that now predominate in empirical studies of the two-way relations between money or monetary policy and the broader macroeconomy.

Sargent is the father of modern structural macroeconometrics. He has shown how to characterize and estimate modern macroeconomic models relying on full microeconomic foundations and he has demonstrated the power of this approach in numerous applications. More generally, Sargent has pioneered the empirical study of expectations formation. He has not only demonstrated how active expectations can be incorporated into empirical models, but has also been at the forefront of further work on expectations formation itself, by considering many alternatives, including learning. Sargent has made substantive contributions to the study of monetary policy in his analyses of historical inflation episodes throughout the world.

Sims is the father of vector autoregressions (VARs) as an empirical tool in macroeconomics. This has become an indispensable tool for applied researchers, alongside structural econometrics. Sims spearheaded the use of VARs as an overall approach for studying macroeconomic aggregates: for interpreting time series, for forecasting, and for policy analysis. Since his early papers in the 1970s, Sims has contributed in many ways to the further development of VAR methodology and to its successful application. VAR analysis has provided a prolific means of identifying macroeconomic shocks to variables like technology and monetary policy, and of examining the causal effects of such shocks.

In their entirety, the research contributions of Sargent and Sims are not merely always and everywhere central in empirical macroeconomic research - it would be nearly impossible to imagine the field without them. Thomas J. Sargent and Christopher A. Sims are awarded the 2011 Sveriges Riksbank Prize in Economic Sciences in Memory of Alfred Nobel

for their empirical research on cause and effect in the macroeconomy. 


\section{References}

Bernanke, Ben S., (1986), "Alternative Explanations of the Money-Income Correlation", Carnegie-Rochester Conference Series on Public Policy 25, pp. 49-99.

Blanchard, Olivier J. and Danny Quah, (1989), "The Dynamic Effects of Aggregate Demand and Supply Disturbances", American Economic Review 79, pp. 655-73.

Blanchard, Olivier J. and Roberto Perotti, (2002), "An Empirical Characterization of the Dynamic Effects of Changes in Government Spending and Taxes on Output", Quarterly Journal of Economics 117, pp. 1329-1368.

Calvo, Guillermo A., (1983), "Staggered Prices in a Utility-Maximizing Framework", Journal of Monetary Economics 12, pp. 383-98

Canova, Fabio and Gianni De Nicolò, (2002), "Monetary Disturbances Matter for Business Fluctuations in the G-7", Journal of Monetary Economics 49, pp. 1131-59

Christiano, Lawrence J., Martin Eichenbaum and Charles L. Evans, (1999), "Monetary Policy Shocks: What Have We Learned and to What End?", Handbook of Macroeconomics, Volume 1A, pp. 65-148, Amsterdam, New York and Oxford: Elsevier Science, North-Holland.

Del Negro, Marco and Frank Schorfheide, (2004), "Priors from General Equilibrium Models for VARs", International Economic Review 45, pp. 64373.

Doan, Thomas, Robert B. Litterman and Christopher A. Sims, (1986), "Forecasting and Conditional Projection Using Realistic Prior Distribution", Federal Reserve Bank of Minneapolis, Staff Report: 93.

Engle, Robert F. and Clive W.J. Granger, (1987), "Co-integration and Error Correction: Representation, Estimation and Testing", Econometrica 55, pp. 251-276.

Evans, George W. and Seppo Honkapohja, (2001), Learning and Expectations in Macroeconomics, Princeton, NJ and Oxford: Princeton University Press.

Faust, Jon, (1998), "The Robustness of Identified VAR Conclusions about Money", Carnegie-Rochester Conference Series on Public Policy 49, pp. 20744.

Galí, Jordi, (1999), "Technology, Employment, and the Business Cycle: Do Technology Shocks Explain Aggregate Fluctuations?", American Economic Review 89, pp. 249-71. 
Galí, Jordi and Mark Gertler, (1999), "Inflation Dynamics: A Structural Econometric Analysis", Journal of Monetary Economics 44, pp. 195-222.

Granger, Clive W.J., (1969), "Investigating Causal Relations by Econometric Models and Cross-spectral Methods", Econometrica 37, pp. 424-438

Grossman, Sanford J. and Joseph E. Stiglitz, (1980), "On the Impossibility of Informationally Efficient Markets", American Economic Review 70, pp. 393-408.

Hansen, Lars P. and Thomas J. Sargent, (1980), "Formulating and Estimating Dynamic Linear Rational Expectations Models", Journal of Economic Dynamics and Control 2, pp. 7-46.

Hansen, Lars P. and Thomas J. Sargent, (2008), Robustness, Princeton, NJ and Oxford: Princeton University Press.

Litterman, Robert B., (1986), "Forecasting with Bayesian Vector Autoregressions - Five Years of Experience", Journal of Business and Economic Statistics 4, pp. 25-38.

Lucas, Robert E. Jr., (1972), "Expectations and the Neutrality of Money", Journal of Economic Theory 4, pp. 103-24

Lucas, Robert E. Jr., (1973), "Some International Evidence on OutputInflation Tradeoffs", American Economic Review 63, pp. 326-34

Lucas, Robert E. Jr., (1976), "Econometric Policy Evaluation: A Critique", Carnegie-Rochester Conference Series on Public Policy 1, pp. 19-46.

Lucas, Robert E. Jr. and Thomas J. Sargent, (1981), Rational Expectations and Econometric Practice, Minneapolis MN, University of Minnesota Press.

Marcet, Albert and Thomas J. Sargent, (1989a), "Convergence of LeastSquares Learning in Environments with Hidden State Variables and Private Information", Journal of Political Economy 97, pp. 1306-22.

Marcet, Albert and Thomas J. Sargent, (1989b), "Least-Squares Learning and the Dynamics of Hyperinflation", in William Barnett, John Geweke and Karl Shell (eds.) Sunspots, Complexity and Chaos, Cambridge; New York and Melbourne: Cambridge University Press.

Primiceri, Giorgio E., (2006), "Why Inflation Rose and Fell: PolicyMakers' Beliefs and U.S. Postwar Stabilization Policy", Quarterly Journal of Economics 121, pp. 867-901.

Quah, Danny and Thomas J. Sargent, (1993), "A Dynamic Index Model for Large Cross Sections", NBER Studies in Business Cycles, vol. 28. Chicago, IL and London: University of Chicago Press. 
Romer, Christina D. and David Romer, (1989), "Does Monetary Policy Matter? A New Test in the Spirit of Friedman and Schwartz", NBER Macroeconomics Annual, Cambridge MA: MIT Press.

Sargent, Thomas J., (1971), "A Note on the 'Accelerationist' Controversy", Journal of Money Credit and Banking 3, pp. 721-25.

Sargent, Thomas J., (1973), "Rational Expectations, the Real Rate of Interest, and the Natural Rate of Unemployment", Brookings Papers on Economic Activity 2, pp. 429-72.

Sargent, Thomas J., (1976), "A Classical Macroeconometric Model for the United States", Journal of Political Economy 84, pp. 207-37.

Sargent, Thomas J., (1977), "The Demand for Money During Hyperinflations under Rational Expectations: I", International Economic Review 18, pp. 59-82.

Sargent, Thomas J., (1978a), "Rational Expectations, Econometric Exogeneity, and Consumption", Journal of Political Economy 86, pp. 673-700.

Sargent, Thomas J., (1978b), "Estimation of Dynamic Labor Demand Schedules under Rational Expectations", Journal of Political Economy 86, pp. 1009-44.

Sargent, Thomas J., (1979), Macroeconomic Theory, New York: Academic Press.

Sargent, Thomas J., (1983), "The Ends of Four Big Inflations," in Roberth E. Hall (ed.), Inflation: Causes and Effects, University of Chicago Press, pp. 41-97.

Sargent, Thomas J., (1987), Dynamic Macroeconomic Theory, Cambridge, MA: Harvard University Press.

Sargent, Thomas J., (1989), "Two Models of Measurements and the Investment Accelerator", Journal of Political Economy 97, pp. 251-87.

Sargent, Thomas J., (2001), The Conquest of American Inflation, Priceton, NJ and Oxford: Princeton University Press.

Sargent, Thomas J. and Christopher Sims, (1977), "Business Cycle Modeling without Pretending to Have Too Much A Priori Economic Theory", Federal Reserve Bank of Minneapolis, Working Paper 55.

Sargent, Thomas J. and Paolo Surico, (2011), "Two Illustrations of the Quantity Theory of Money: Breakdowns and Revivals", American Economic Review 101, pp. 109-28.

Sargent, Thomas J. and Neil Wallace, (1973), "The Stability of Models of Money and Growth with Perfect Foresight", Econometrica 41, pp. 1043-48. 
Sargent, Thomas J. and Neil Wallace, (1975), "'Rational' Expectations, the Optimal Monetary Instrument, and the Optimal Money Supply Rule", Journal of Political Economy 83, pp. 241-54.

Sargent, Thomas J. and Neil Wallace, (1976), "Rational Expectations and the Theory of Economic Policy", Journal of Monetary Economics 2, pp. $169-83$.

Sargent, Thomas J. and Neil Wallace, (1981), "Some Unpleasant Monetarist Arithmetic", Federal Reserve Bank of Minneapolis Quarterly Review 5, pp. $1-17$.

Sargent, Thomas, Noah Williams and Tao Zha, (2006), "Shocks and Government Beliefs: The Rise and Fall of American Inflation", American Economic Review 96, pp. 1193-1224.

Sims, Christopher A., (1972), "Money, Income, and Causality", American Economic Review 62, pp. 540-52.

Sims, Christopher A., (1980), "Macroeconomics and Reality", Econometrica 48 , pp. 1-48.

Sims, Christopher A., (1986), "Are Forecasting Models Usable for Policy Analysis?", Minneapolis Federal Reserve Bank Quarterly Review 10, pp. 216.

Sims, Christopher A., (1987), "A Rational Expectations Framework for Short-run Policy Analysis", in Kenneth J. Singleton (ed.), New Approaches to Monetary Economics, Proceedings of the Second International Symposium in Economic Theory and Econometrics, pp. 293-308, Cambridge; New York and Melbourne: Cambridge University Press.

Sims, Christopher A., (1989), "Models and Their Uses", American Journal of Agricultural Economics 71, pp. 489-94.

Sims, Christopher A., (1992), "Interpreting the Macroeconomic Time Series Facts: The Effects of Monetary Policy", European Economic Review 36, pp. $975-1011$.

Sims, Christopher A., (1993), "Business Cycles, Indicators, and Forecasting", NBER Studies in Business Cycles 28, pp. 179-204.

Sims, Christopher A., (1994), "A Simple Model for the Study of the Determination of the Price Level and the Interaction of Monetary and Fiscal Policy," Economic Theory 4, pp. 381-399.

Sims, Christopher A., (2003), "Implications of Rational Inattention", Journal of Monetary Economics 50, pp. 665-90.

Sims, Christopher A., (2006), "Rational Inattention: Beyond the LinearQuadratic Case", American Economic Review 96, pp. 158-163. 
Sims, Christopher A, James H. Stock and Mark W. Watson, (1990), "Inference in Linear Time Series Models with Some Unit Roots", Econometrica 58, pp. 113-144.

Sims, Christopher A. and Tao Zha, (2006), "Were There Regime Switches in U.S. Monetary Policy?", American Economic Review 96, pp. 54-81.

Stock, James H. and Mark W. Watson, (2001), "Vector Autoregressions", Journal of Economic Perspectives 15, pp. 101-15.

Uhlig, Harald, (2005), "What Are the Effects of Monetary Policy on Output? Results from an Agnostic Identification Procedure", Journal of Monetary Economics 52, pp. 381-419.

Woodford, Michael, (1994), "Monetary Policy and Price Level Determinacy in a Cash-in-Advance Economy", Economic Theory 4, pp. 345-380. 